\section{QUARTR: A FORTRAN IV subroutine to calculate quarter life}

JACQUES P. J. MAURISSEN

Department of Radiation Biology and Biophysics, School of Medicine and Dentistry,

University of Rochester, Rochester, New York 14642

In 1957, Herrnstein and Morse described a measure that characterizes responding in fixed-interval per-

This project was supported by NIMH Grant MH11752, ES-01248 and in part by a contract with the USDOE and was assigned Report No. UR-3490-1367. formance. This index, called quarter life of responses, represents the time taken by the subject to emit the first one-fourth of the total responses within that particular interval. If the rate of responding is constant throughout the interval, the quarter life is equal to one-fourth of the interval. If the rate of response is positively accelerated through the interval, the index is greater than one-fourth of the interval. If it is negatively accelerated within the interval, the index is smaller than one-fourth of the interval. Quarter life is still used (Bignami \& Gatti, 1969; Byrd, 1972; Carney, 1977; Dukich \& Lee, 1973; Goldberg \& Kelleher, 1976; Goldberg \& Tang, 1977; Kelleher \& Goldberg, 1977; Lattal \& Bryan, 1976; Spealman, Goldberg, Kelleher,

Table 1

FORTRAN IV Subroutine for the Calculation of the Quarter Life

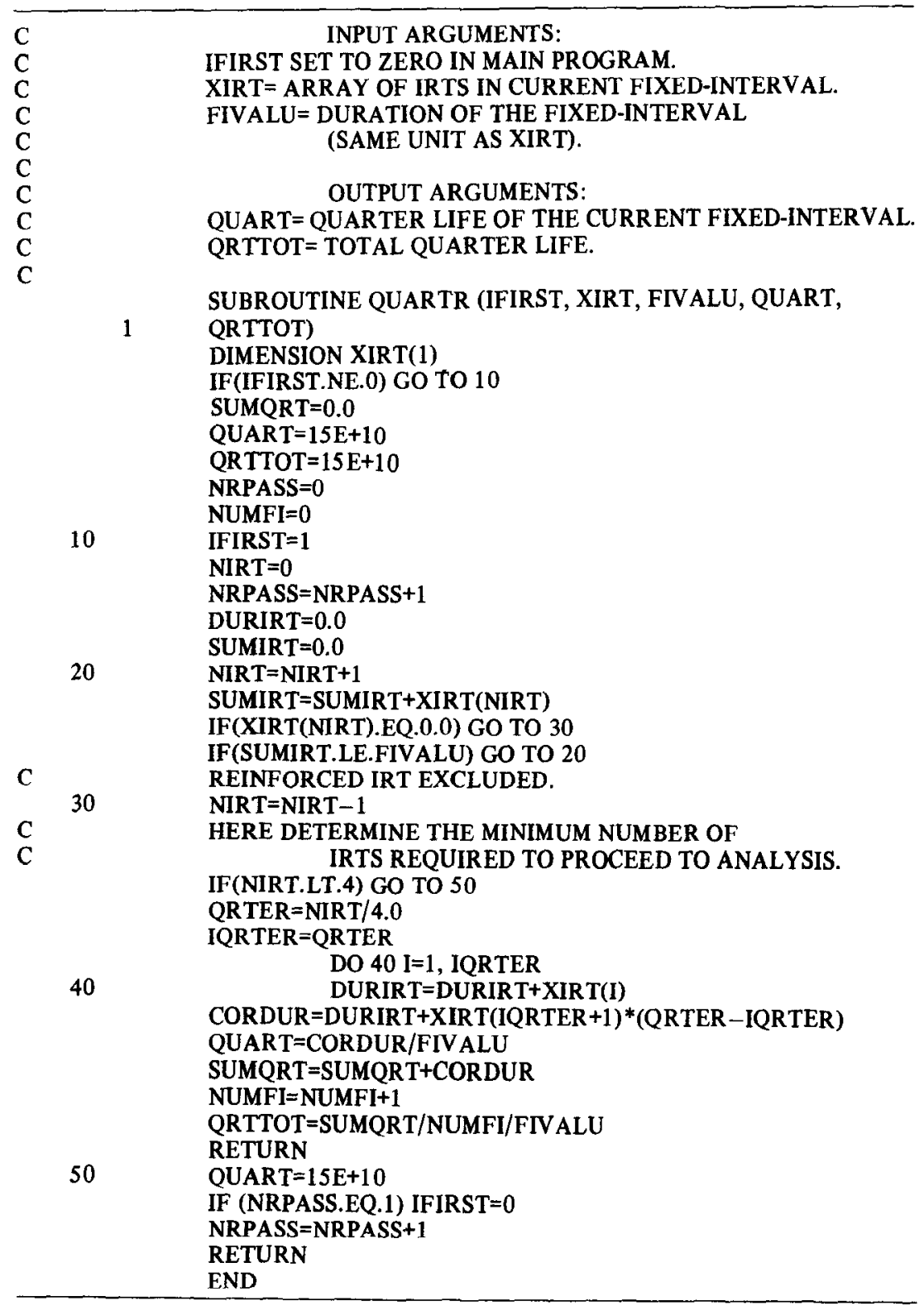


Goldberg, \& Charlton, 1977). Table 1 gives the listing of a FORTRAN IV subroutine that allows calculation of this index of performance.

The first three arguments represent inputs to the subroutine. The first argument (IFIRST) is an integer that has to be given the value zero in the main program before calculating the quarter life for each session. The second argument (XIRT) is the array containing all the interresponse times of this interval, including the reinforced interresponse time. This last variable has to be dimensioned in the main program to the maximum possible number of interresponse times in any fixed interval. It is advised to zero the array first before inserting the interresponse times in it, so that unused locations of the array will be zeroes. The third input argument (FIVALU) is the value of the fixed interval.

Two arguments are returned from the subroutine to the main program. They represent the quarter life of a particular interval (QUART) or of all the fixed intervals analyzed up to that point (QRTTOT) since the last time the variable IFIRST was reset to zero in the main program.

When the number of interresponse times cannot be evenly divided by 4 , a linear interpolation is performed. Care is taken in the subroutine to discard fixed intervals containing less than a certain number of interresponse times (after the reinforced interresponse time was excluded). In the program presented in Table 1 , this number has been arbitrarily set to 4 , but any value can be used. If there are less than the minimum number of interresponse times required, this interval is skipped during analysis, and stars are printed when writing the value of the current fixed-interval index of curvature and the value of the total index is not affected. An example of how to use the subroutine is shown in Table 2.

Requirements. This program has been developed on a Digital Equipment Corporation PDP-12 computer. It also runs on PDP-8/E, DEC-10 system and IBM 360 without modifications. It is written in ANSI standard FORTRAN IV and should work on any other computer that supports FORTRAN IV.

The time required to run the program will vary greatly according to the type of computer used and the amount of data to be analyzed. The subroutine occupies less than 500 12-bit words of memory after it has been compiled.

Availability. Copies of the source listing may be obtained without charge from Jacques P. J. Maurissen, Department of Radiation Biology and Biophysics, School of Medicine and Dentistry, University of Rochester, Rochester, New York 14642.

\section{REFERENCES}

Bignami, G., \& Gatti, G. L. Analysis of drug effects on multiple fixed ratio 33-fixed interval $5 \mathrm{~min}$ in pigeons. Psychopharmacologia (Berlin), 1969, 15, 310-332.
Table 2

FORTRAN IV Program to Run the Subroutine QUARTR

DIMENSION XIRT(10),ZIRT(50)

DATA ZIRT/5.9,2.1,3.4,0.,0.,0.,0.,0.,0.,0.,

1 1.,1.,1.,1.,1.,1.,1.,1.,1.,1.,

$2 \quad 1.6,8.9,0 ., 0 ., 0 ., 0 ., 0 ., 0 ., 0 ., 0$. ,

$3 \quad 4.2,1 ., 1 ., .7, .8, .5,2.1,0 ., 0 ., 0$.,

$4 \quad 6.5,1.4,1 ., .2, .2, .15, .15, .1, .15, .21$

IFIRST $=0$

FIVALU $=10.0$

$\mathrm{N}=1$

IRTTOT $=10$

DO $20 \mathrm{I}=1,5$

$\mathrm{L}=0$

DO $10 \mathrm{~K}=\mathrm{N}$, IRTTOT

$\mathrm{L}=\mathbf{L}+1$

$10 \quad$ XIRT(L) $=Z \operatorname{ZIRT}(\mathrm{K})$

$\mathrm{N}=\mathrm{N}+10$

IRTTOT $=$ IRTTOT +10

CALL QUARTR(IFIRST,XIRT,FIVALU,QUART,

1 QRTTOT)

20 WRITE $(4,30)$ QUART,QRTTOT

30 FORMAT(1H0, 'QUARTER LIFE FOR CURRENT

1 FI = ',F6.3,/,1H , 'TOTAL QUARTER LIFE =

$2 \quad$,F6.3)

STOP

END

BYRD, L. D. Responding in squirrel monkey under second-order schedules of shock delivery. Joumal of the Experimental Analysis of Behavior, 1972, 18, 155-167.

CARNEY, J. M. Pargylin-induced increases in sensitivity to the effects of drugs on operant behavior in pigeons. Psychopharmacology, 1977, 52, 97-102.

Dukich, T. D., \& LEE, A. E. A comparison of measures under fixed-interval schedules. Joumal of the Experimental Analysis of Behavior, 1973, 20, 281-290.

Goldberg, S. R., \& Kelleher, R. T. Behavior controlled by scheduled injections of cocaine in squirrel and rhesus monkeys. Journal of the Experimental Analysis of Behavior, 1976, 25, 93-104.

GoldberG, S. R., \& TANG, A. H. Behavior maintained under second-order schedules of intravenous morphine injection in squirrel and rhesus monkeys. Psychopharmacology, 1977, 51, 235-242.

Herrnstein, R. J., \& Morse, W. H. Effects of pentobarbital on intermittently reinforced behavior. Science, 1957, 157, 929-931.

KELleHeR, R. T., \& Goldberg, S. R. Fixed-interval responding under second-order schedules of food presentation or cocaine injection. Joumal of the Experimental Analysis of Behavior, $1977,28,221-231$.

LATTAi, K. A., \& BRYAN, A. J. Effects of concurrent responseindependent reinforcement on fixed-interval schedule of performance. Journal of the Experimental Analysis of Behavior, 1976, 26, 495-504.

Spealman, R. D., Goldberg, S. R., Kelleher, R. T., Goldgerg, D. M., \& Charlton, J. P. Some effects of cocaine and two cocaine analogs on schedule-controlled behavior of squirrel monkeys. Journal of Pharmacology and Experimental Therapeutics, 1977, 202, 500-509.

(Accepted for publication May 2, 1978.) 